\title{
CHANGES IN TOTAL ACTIVE CENTRES ON PARTICLE SURFACES DURING COAL PYROLYSIS, GASIFICATION AND COMBUSTION
}

\author{
Stanisław Gil ${ }^{*}$, Piotr Mocek, Wojciech Bialik \\ Silesian University of Technology, Department of Metallurgy, Group of Process Energy, \\ ul. Krasinskiego 8, 40-019 Katowice, Poland
}

\begin{abstract}
In the paper, on the basis of our studies and the available literature data, a model of changes in the number of active centers corresponding to the structure of the reactive coal particle has been developed. A new distribution function that links the specific surface area of a particle with its porosity and reaction degree has been proposed. An equation for estimation of changes in this parameter during the reaction, on the basis of the initial value, has been presented. In the range of our data and the analysis of the literature data, the model, with satisfactory accuracy, describes internal structural changes of coal and coal char particles. The present results may constitute a basis for complex modelling of coal conversion processes.

Based on the results it was found that the total active centres are related to the internal surface area and porosity of the particle. For a specific coal type, this value depends on the porosity, true density and size of the particle. Changes in total active centres, when these structural properties during thermal conversion of coal are considered, are described in equations.
\end{abstract}

Keywords: coal, active centers, porosity

\section{INTRODUCTION}

The reaction of coal (regardless of its type) with the reactant molecule occurs on the actual available internal surface of the grain. The course of reaction and reactivity of the grain is affected by: the heterogeneity of the surface, its defects its chemical and crystalline structure. Depending on the geometric arrangement of atoms on solid surfaces and the nature of these atoms at different points of the surface, forces are different in character and values. As a result, there are places on the surface with a different potential from one needed to initiate a chemical reaction. Regions with a low threshold of entry into a chemical reaction are known as active centers or active sites. The concept of active centres in analysing reactions of coal with oxygen was used for the first time by Laine et al. (1963).

In records of heterogeneous coal combustion reactions, many authors (Croiset et al., 1996; Croiset et al., 1998; De Soete, 1990; Johnson, 1987; Krammer and Sarofim, 1994; Stanmore, 1991) use the term 'active centres' (e.g. $[\mathrm{C}],[\mathrm{CO}],[\mathrm{CN}],[\mathrm{CNO}]$ ) on a carbon matrix. However, they do not determine initial total active centers and their changes during the combustion process and only use active centre fractions (Croiset et al., 1998; De Soete, 1990; Krammer and Sarofim, 1994). A part of a coal char combustion model has been presented as four heterogeneous reactions with active centres:

$$
\begin{gathered}
\mathrm{O}_{2}+2[\mathrm{C}] \rightarrow 2[\mathrm{CO}], \\
{[\mathrm{CO}] \rightarrow \mathrm{CO}+\mathrm{C}_{\mathrm{f}},}
\end{gathered}
$$




$$
\begin{gathered}
2[\mathrm{CO}] \rightarrow \mathrm{CO}_{2}+\mathrm{C}+\mathrm{C}_{\mathrm{f}}, \\
\mathrm{O}_{2}+[\mathrm{C}]+[\mathrm{CN}] \rightarrow[\mathrm{CO}]+[\mathrm{CNO}] .
\end{gathered}
$$

Particular active centres $\vartheta_{i}$ have been defined as follows:

$$
\begin{gathered}
\vartheta_{\mathrm{C}}=[\mathrm{C}] / S, \\
\vartheta_{\mathrm{CO}}=[\mathrm{CO}] / S, \\
\vartheta_{\mathrm{CN}}=[\mathrm{CN}] / S, \\
\vartheta_{\mathrm{CNO}}=[\mathrm{CNO}] / S,
\end{gathered}
$$

where $S$ is a sum of all concentrations of occupied active centres, described in the model:

$$
S=[\mathrm{C}]+[\mathrm{CO}]+[\mathrm{CN}]+[\mathrm{CNO}] .
$$

Subsequently, in kinetic equations describing coal char combustion, active centres were applied in accordance with the methodology assumed for heterogeneous reactions.

In pertinent literature, there are very few reports related to concentrations of active sites in coal chars, and there is little information regarding coal pyrolysis during preparation of coal char for hydrogasification. Blackwood and McCarthy (1966), Johnson (1987), while conducting hydrogasification experiments, recorded a decrease in coal char reactivity with an increase in its devolatilization temperature. They found the decrease to be dependent on changes in active centre concentrations. They assumed the number of active centres of particle, $S$, as the arithmetic product of the total specific surface area of the coal char particle, $A$, multiplied by their surface concentration, $S_{0}$. In the case of brown coal particle devolatilization, when the devolatilization temperature, $T_{\mathrm{p}}$, exceeds the gasification temperature, the authors propose formulating a relationship of the active centre number and temperature in the form of an exponential function:

$$
S=A S_{0} \exp \left(-\frac{E}{R T_{\mathrm{p}}}\right), \text { mole }_{\mathrm{a} . \mathrm{c}} \cdot \mathrm{mole}_{\mathrm{C}} \text { or a.c. } / \mathrm{kg}_{\mathrm{C}}
$$

where: $A, \mathrm{~m}^{2} / \mathrm{mole}_{\mathrm{C}}$ or $\mathrm{m}^{2} / \mathrm{kg}_{\mathrm{C}} ; S_{0}$, mole a.c. $/ \mathrm{m}^{2}$ or a.c. $/ \mathrm{m}^{2}$, gas constant $R, \mathrm{~kJ} /($ mole K). Johnson (1987) determined the activation energy $E=39.36 \mathrm{~kJ} / \mathrm{mole}$, while according to Blackwood et al. (1966), $E=$ $83.74 \mathrm{~kJ} / \mathrm{mole}$. The above equation can be applied for coal nitrogen devolatilization in the temperature range of $1200-1373 \mathrm{~K}$ as well as for hydrogasification at $1200 \mathrm{~K}$ and the pressure of up to $3.5 \mathrm{MPa}$.

Gil (2002) gives an equation for calculations of total active centres of coal char, depending on porosity $\varepsilon$ as a function of the particle reaction degree, $U$, the internal specific surface area, $A$, as a function of the particle reaction degree and its diameter, $d$, was proposed

$$
S=K A d^{3}(1-\varepsilon), \text { kmole a.c. } / \mathrm{kg}_{\mathrm{C}} \text { or a.c. } / \mathrm{kg}_{\mathrm{C}}
$$

where: $K=32.22$ kmole a.c. $/ \mathrm{m}^{5}$ or $K=1.95 \cdot 10^{28}$ a.c. $/ \mathrm{m}^{5}$. Based on Stanmore`s paper (1991), it was assumed that

$$
\varepsilon=\varepsilon_{0}+U\left(1-\varepsilon_{0}\right)
$$

and

$$
A=A_{0}(1+2.5 U)(1-U), \mathrm{m}^{2} / \mathrm{kg}_{\mathrm{C}}
$$

Where, $\varepsilon_{0}$, and, $A_{0}$, are porosity and internal specific surface area for $U=0$, respectively, while the particle react degree $U=1-m(t) / m_{0}$ was determined on the basis of the initial mass $m_{0}$ and the mass, $m(t)$, after the time, $t$. Equation (11) can be applied for bituminous coal char combustion within the temperature and pressure ranges of $1073-1373 \mathrm{~K}$ and $0.1-1.5 \mathrm{MPa}$, respectively. 
Modelling of flow processes during reactions on carbon surface should allow for true particle properties. An especially important feature is pore structure in the particle and a resulting number of carbon atoms able to form, under given conditions, stable products of the discussed processes. The properties of both internal and external surface areas as well as the spatial distribution of particle pores directly adjacent to free gas space determine the number of access zones for gas reactants. A correct determination of the surface structure and mechanisms of heterogeneous reactions in the particle would enable one to formulate a uniform model of coal devolatilization, gasification and combustion. The studies presented in this paper aimed at achieving this goal.

\section{DETERMINATION OF POROSITY CHANGES}

There have been many studies on the kinetics of volatile element release during coal pyrolysis (Anthony and Howard, 1976; Kowol and Tomeczek, 1988; Suuberg et al., 1979), and a few are cited in the present paper. However, there are a relatively small number of papers describing modelling of pore structure kinetics in this process (Gil, 2000; Kathandaraman and Simons, 1984; Mlonka, 1992; Simons, 1984; Tomeczek and Gil, 1995, 2003).

Simons (1984) as well as Kothandaraman and Simons (1984) belong to a small group of researchers that investigated the impact of heating rate and exposure temperature on pore change kinetics. Simons (1984) proposed the following kinetic equation:

$$
\frac{d \varepsilon}{d t}=k_{1}\left(\varepsilon_{\infty}-\varepsilon\right)
$$

where the kinetic coefficient, $k$, determines the upper limit for the pyrolysis range described by Anthony and Howard (1976). Equation (14) describes pore structure changes that are parallel to the kinetics of particle mass loss during devolatilization, which was never proven.

For a description of quantity and quality pore changes during pyrolysis, Tomeczek and Gil (1995, 2003) proposed the following kinetic equation

$$
\frac{d \varepsilon}{d t}=\sum_{\mathrm{j}=1}^{\mathrm{J}} k_{0 \mathrm{j}}\left(\varepsilon_{\infty \mathrm{j}}-\varepsilon\right) \exp \left(-\frac{E_{\mathrm{j}}}{R T}\right)
$$

Kinetic constants, $k_{0 \mathrm{j}}$, $E_{\mathrm{j}}$, and, $\varepsilon_{\infty}$, for the term $j$ and the number of terms $J$ were determined on the basis of experimental results. The solution of Equation (15) was as follows:

$$
\varepsilon=\sum_{\mathrm{j}=1}^{\mathrm{J}} \boldsymbol{\varepsilon}_{\infty \mathrm{j}}\left[1-\exp \left(-k_{0 \mathrm{j}} M_{\mathrm{j}}\right)\right]
$$

where

$$
M_{j}=\frac{R T^{2}}{\dot{T} E_{\mathrm{j}}}\left[1-2 \frac{R T}{E_{\mathrm{j}}}+6\left(\frac{R T}{E_{\mathrm{j}}}\right)^{2}\right]_{T_{0}}^{T_{1}} \exp \left(-\frac{E_{\mathrm{j}}}{R T}\right)+\left(t-t_{1}\right) \exp \left(-\frac{E_{\mathrm{j}}}{R T_{1}}\right)
$$

The authors propose this pore change model for a wide range of pyrolysis parameters.

Modelling petroleum coke combustion, Stanmore (1991) presented an equation for porosity changes as a function of the particle reaction degree (Eq. (12)) for the temperature range of 1250-1750 K, which was further modified by Visona and Stanmore (1996) with a solid substance volume parameter of the coal char particle in relation to its total volume. In their study on pore structure changes during coal char gasification in air and carbon dioxide, at temperatures $653 \mathrm{~K}$ and $1073 \mathrm{~K}$, Feng and Bhatia (2003) also applied Equation (12). 
Hurt et al. (1991) and Sotirchos (1987) provided their own equations for porosity changes during the gasification process, in which changes depended on the changes in pore and particle diameters.

In the present paper, the authors' aim is to propose a relatively simple equation which may describe porosity changes as a function of the particle reaction degree for all the three processes: coal devolatilization, coal char gasification and combustion. The overall porosity change rate was described as follows

$$
\frac{d \varepsilon}{d U}=k_{2} \varepsilon^{\mathrm{n}}
$$

where exponent, $n$, equals 0 or 1 . After separation of variables and integration of Equation (18) within the initial porosity limits from $\varepsilon_{0}$ to $\varepsilon$ and from $U=0$ to $U$, for $n=0$, the equation is as follows

$$
\varepsilon=\varepsilon_{0}+k_{2} U
$$

while for $n=1$, we have the equation

$$
\varepsilon=\varepsilon_{0} \exp \left(k_{2} U\right)
$$

For marginal conditions $U=1$ and $\varepsilon=1$ in Equation (19), the coefficient $k_{2}=1-\varepsilon_{0}$, while in Equation (20): $k_{2}=-\ln \varepsilon_{0}$. After defining the coefficient $k$, Equation (19) turns to Equation (12), while Equation (20) can be described as follows:

$$
\varepsilon=\varepsilon_{0} \exp \left(-U \ln \varepsilon_{0}\right)
$$

Equations (12) and (21) were verified on the basis of the available literature and experimental data (Gil, 2000, 2003; Johnson, 1975; Tomeczek and Gil, 1995). The characteristics of enriched coals are presented in Table 1. In Table 2, both pyrolysis and coal gasification parameters for seven experimental series are presented.

Table 1. Characteristics of coals

\begin{tabular}{|c|c|c|c|c|c|c|c|c|}
\hline Enriched coal & $\begin{array}{c}W^{a} \\
{[\%]}\end{array}$ & $\begin{array}{c}V^{\text {waf }} \\
{[\%]}\end{array}$ & $\begin{array}{c}A^{\text {wf }} \\
{[\%]}\end{array}$ & $\begin{array}{c}C^{\text {waf }} \\
{[\%]}\end{array}$ & $\begin{array}{c}H^{\text {waf }} \\
{[\%]}\end{array}$ & $\begin{array}{c}S^{a} \\
{[\%]}\end{array}$ & $\begin{array}{c}N^{\text {waf }} \\
{[\%]}\end{array}$ & $\begin{array}{c}\varepsilon_{0} \\
{[\%]}\end{array}$ \\
\hline Siersza (Gil 2000) & 2.6 & 37.7 & 6.9 & 77.0 & 5.1 & 2.5 & 1.51 & 15.8 \\
\hline Niwka (Gil 2000) & 1.9 & 33.8 & 6.0 & 79.5 & 4.1 & 1.7 & 1.6 & 16.4 \\
\hline Janina (Gil 2003) & 3.3 & 33.9 & 8.1 & 77.6 & 3.3 & 1.1 & 1.34 & 14.6 \\
\hline Piast (Gil 2003) & 5.7 & 30.8 & 7.1 & 84.2 & 3.9 & 1.2 & 1.42 & 15.1 \\
\hline
\end{tabular}

Table 2. Process parameters of the considered coals in the analysis of porosity changes

\begin{tabular}{|c|c|c|c|c|c|c|}
\hline No. & Coal type & Process & $\begin{array}{c}T \\
{[\mathrm{~K}]}\end{array}$ & $\begin{array}{c}p \\
{[\mathrm{MPa}]}\end{array}$ & $\begin{array}{c}\dot{T} \\
{\left[\mathrm{~K} \mathrm{~s}^{-1}\right]}\end{array}$ & $\begin{array}{c}\varepsilon_{0} \\
{[\%]}\end{array}$ \\
\hline 1 & Siersza (Gil 2000) & Pyrolysis & 1073 & 0.1 & 20 & 13.34 \\
\hline 2 & Siersza (Gil 2000) & Pyrolysis & 1373 & 0.1 & 20 & 13.34 \\
\hline 3 & Beneficiated Siersza & Pyrolysis & 1073 & 1.0 & 100 & 15.82 \\
\hline 4 & Beneficiated Siersza & Pyrolysis & 1373 & 1.0 & 100 & 15.82 \\
\hline 5 & Anthracite & Gasification & 1200 & 3.5 & - & \\
\hline 6 & Bituminous A & Gasification & 1200 & 3.5 & - & \\
\hline 7 & $\begin{array}{c}\text { Beneficiated Niwka } \\
\text { (Tomeczek and Gil 1995) }\end{array}$ & Pyrolysis & 1373 & 1.0 & 100 & 16.38 \\
\hline
\end{tabular}


Figure 1 is a graphic representation of the above experimental series as a function of the particle reaction degree. The graphic symbols are accompanied by the figures corresponding to the number of the experiment (Table 1). This also regards other figures. Porosities for anthracite and bituminous coal $A$ from Johnson's paper (1975) were determined on the basis of pore specific volumes and the apparent specific volume of the particle, measured during hydrogasification, while in other papers (Mlonka 1992, Tomeczek and Gil 1995), the porosities and values of coal mass loss during volatilization were measured in a direct manner. During both fuel conversion processes, porosity development values of up to 0.3 for the particle reaction degree of about 0.5 can be observed.

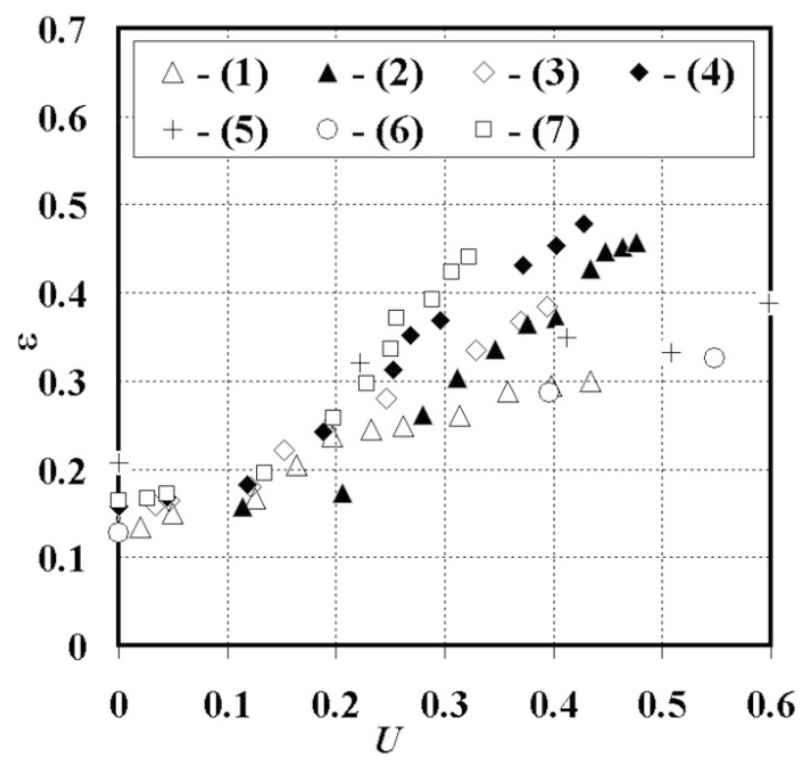

Fig. 1. Porosity as a function of the particle reaction degree

Figure 2 shows the results of porosity change modeling using Equations (12) and (21) for Polish coal particles of various initial porosities (series 1-4). Equation (12) better describes porosity changes during devolatilization at the process temperature of $1373 \mathrm{~K}$, while Equation (21) - at the process temperature of $1073 \mathrm{~K}$, which can be seen in the range of the particle reaction degrees from 0.25 to 0.5 . The impact of the temperature on the selection of porosity change equation is obvious, while the effect of the process pressure increase was not found. In regard to changes in heating rates, there is a reverse correlation between the heating rate increase and the exponent value.

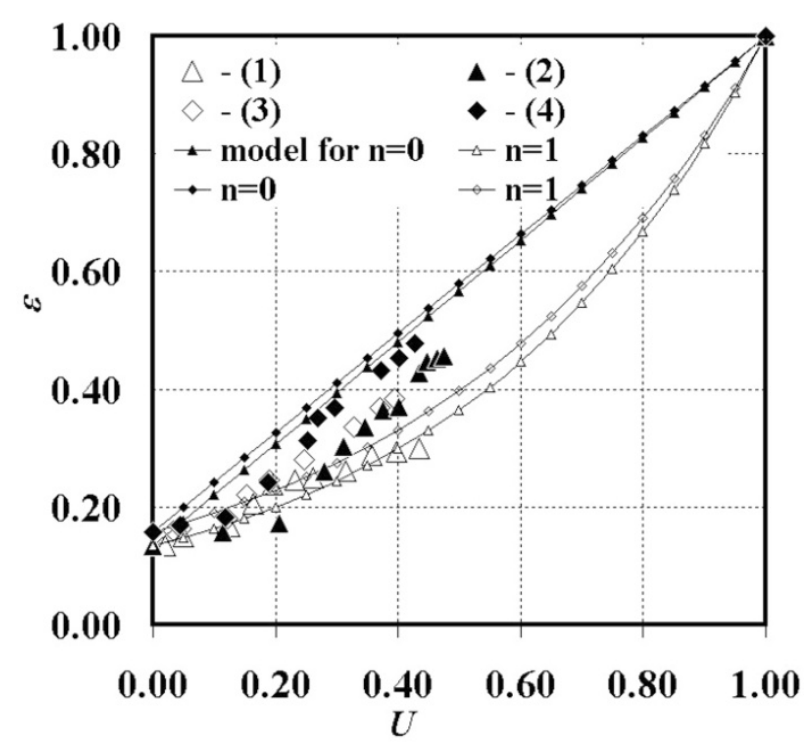

Fig. 2. Model lines and the experimental series 
A statistical analysis of consistency between the experimental and calculated values for both equations is presented in Figure 3. The experimental data for seven various coal types or experimental conditions were determined.

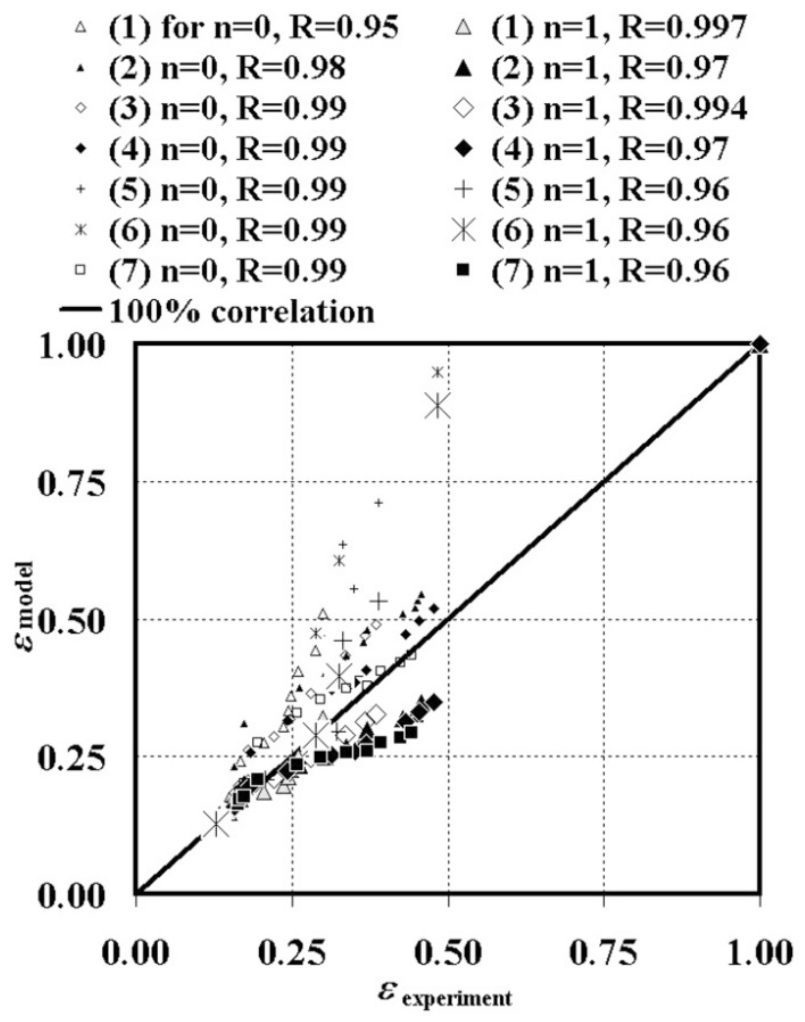

Fig. 3. Correlation of the models and the experimental series

For devolatilization processes, Equation (21) gives more precise results, while in the case of combustion and gasification, higher values of correlation coefficients were found for Equation (12). Nevertheless, in both cases, a sufficient strong correlation between both models and experimental series (the correlation coefficient $R>0.94$ ) was obtained. Thus, both equations can be successfully applied for porosity change description in regard to coal devolatilization, combustion and gasification.

The relationship between porosity changes and the pore internal surface area in the above three processes appears to be an important issue.

\section{DETERMINATION OF INTERNAL SURFACE AREA CHANGES}

For an ideal, cylindrical pore of known porosity, the relationship between porosity and internal surface changes is described as follows (Smith 1970)

$$
A=\frac{2 \varepsilon}{\rho_{\mathrm{p}} r_{\mathrm{p}}}, \mathrm{m}^{2} / \mathrm{kg}
$$

where $\rho_{\mathrm{p}}, \mathrm{kg} / \mathrm{m}^{3}$, is the coal apparent density and, $r_{\mathrm{p}}, \mathrm{m}$, is the mean pore radius.

However, the shapes and the internal structures of channels for gas entrance are much more complex. Typical studies of porosity changes are based on certain model shapes or mathematical descriptions of open pore development (Gil, 2000; Kothandaraman and Simons, 1984; Mlonka, 1992; Simons, 1984; Tomeczek and Gil, 1995). 
Hurt et al. (1991) proposed to make the specific surface area dependent on porosity and radius in the following equation:

$$
A=4 \pi k_{3}(1-\varepsilon)\left(\frac{1}{r_{\min }}-\frac{1}{r_{\max }}\right), \mathrm{m}^{2} / \mathrm{kg}
$$

where: $k_{3}$, is a constant and equals $7.16 \mathrm{~m}^{3} / \mathrm{kg}$; while $r_{\min }, r_{\max }$ are the minimum and maximum pore radi, respectively.

On the other hand, Sotirchos (1987) linked the porosity $\varepsilon$, the pore radius $r$ and the number of spherical pores in the pore volume $n_{1}, \mathrm{~m}^{-3}$, in the following equation:

$$
A=4 \pi \varepsilon r^{2} n_{1}, \mathrm{~m}^{2} / \mathrm{m}^{3} .
$$

Contrary to Equations (22) - (24), Stanmore (1991) associated the internal specific surface area with the particle reaction degree in Equation (13), which is particularly useful for thermal coal conversion modelling.

In the present paper, we assumed that the porosity and the internal surface area can be linked by a certain partition function in the form that enables modelling of internal structure changes for a wide range of reaction degrees and coal types. On the basis of this thesis, we searched for a function to link both parameters in the form of reduced porosity $\left(\varepsilon \cdot \varepsilon_{0}^{-1}\right)$ and the surface area $\left(A \cdot A_{0}{ }^{-1}\right)$, which should also include material properties of the internal structure of the particle. Analyzing a series of equations, the porosity and the internal surface area were linked in the following way:

$$
\frac{A}{A_{0}}=\left(\frac{\varepsilon}{\varepsilon_{0}}\right)^{2} \exp \left[a\left(1-\frac{\varepsilon}{\varepsilon_{0}}\right)\right],
$$

where, $a$, is a matching parameter. Figure 4 presents a comparison of our experimental data obtained for Niwka coal with the model of internal surface area changes, where the correlation coefficient of the obtained equation is $R=0.88$. The analysis of Figure 4 shows a property, according to which internal surface area development occurs with the progress of devolatilization process. Pore linking, combustion and devolatilization are associated with a decrease in the values $A / A_{0}$. In the calculations, Equations (12) and (21) were applied in order to determine their accuracy in modelling the impact of the reaction degree on the internal surface area changes. For $n=1$, Equation (25), related to the surface area and the burn-off level, takes the following form:

$$
\frac{A}{A_{0}}=\exp \left\{-2 U \ln \varepsilon_{0}+a_{1}\left[1-\exp \left(-U \ln \varepsilon_{0}\right)\right]\right\}
$$

while for $\mathrm{n}=0$, it is

$$
\frac{A}{A_{0}}=k_{2}\left(\frac{\varepsilon_{0}+U\left(1-\varepsilon_{0}\right)}{\varepsilon_{0}}\right)^{2} \exp \left(\frac{-a_{0} U\left(1-\varepsilon_{0}\right)}{\varepsilon_{0}}\right)
$$

The values of the matching constant, $a$, for bituminous and brown coals are $a_{1}=1 \pm 0.05$, while $a_{0}=0.65 \pm 0.05$. For active carbons, coals and coal chars of high microporosity as well as for anthracites, the values of both matching constants are lower by approximately $40 \%$.

The results of the studies (Agrawal and Sears, 1980; Floes et al., 1988; Johnson, 1975; Kulaots et al., 2004; Suuberg et al., 2003;) and our study results were used for verification of the proposed Equations (26) and (27). In Table 3, selected initial parameters are presented. 


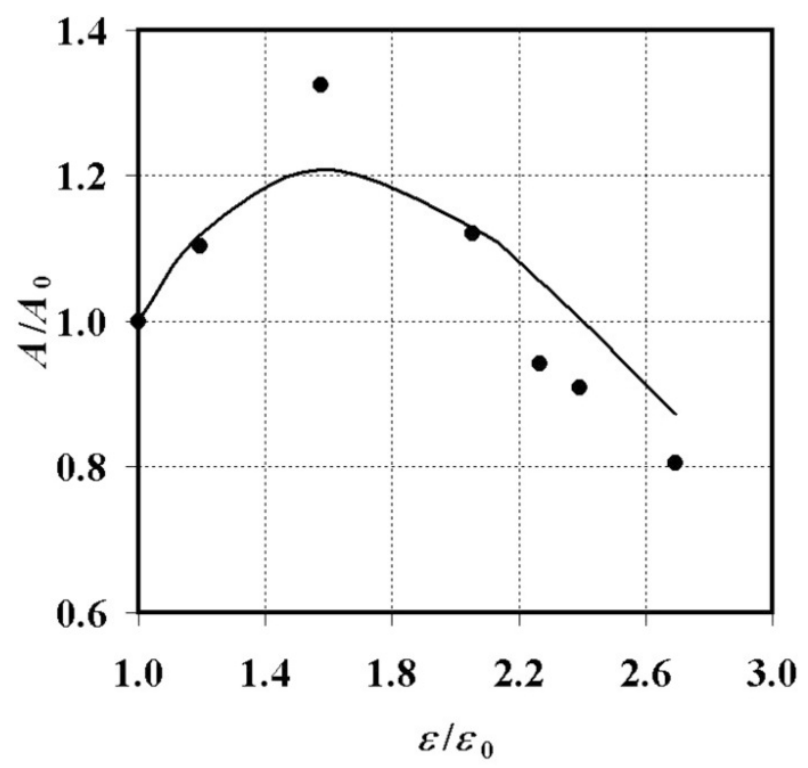

Fig. 4. Relationship between the relative pore surface and the porosity during gasification for Niwka coal

Table 3. Process parameters of the considered coals in the analysis of the internal surface area changes

\begin{tabular}{|c|c|c|c|c|c|c|}
\hline No. & Coal type & $T[\mathrm{~K}]$ & $p[\mathrm{MPa}]$ & Gas solution & $\begin{array}{c}A_{0} \cdot 10^{-3} \\
\mathrm{~m}^{2} / \mathrm{kg}\end{array}$ & Reference \\
\hline 8 & Brown & $1033-1200$ & 3.5 & $\mathrm{H}_{2} \mathrm{O} / \mathrm{H}_{2}=1$ & 140 & Agrawal and Sears (1980) \\
\hline 9 & Bituminous I & $1033-1200$ & 3.5 & $\mathrm{H}_{2} \mathrm{O} / \mathrm{H}_{2}=1$ & 530 & Johnson (1975) \\
\hline 10 & Anthracite & $1033-1200$ & 3.5 & $\mathrm{H}_{2} \mathrm{O} / \mathrm{H}_{2}=1$ & 550 & Johnson (1975) \\
\hline 11 & Pocahontas & 789 & 0.1 & $\mathrm{O}_{2} / \mathrm{N}_{2}=0.267$ & 600 & Kulaots et al. (2002) \\
\hline 12 & Upper freeport & 750 & 0.1 & $\mathrm{O}_{2} / \mathrm{N}_{2}=0.267$ & 450 & Kulaots et al. (2002) \\
\hline 13 & Brown & $1173-1373$ & 0.1 & $\mathrm{CO}_{2}$ & 131 & Agrawal and Sears (1980) \\
\hline 14 & Pittsbourgh & 773 & 0.1 & $\mathrm{O}_{2} / \mathrm{Ar}=1 / 48$ & 140 & Suuberg et al. (2003) \\
\hline 15 & Pittsbourgh & 1123 & 0.1 & $\mathrm{CO}_{2} / \mathrm{Ar}=2 / 23$ & 140 & Suuberg et al. (2003) \\
\hline 16 & Pittsbourgh & 1023 & 0.1 & $\mathrm{NO}^{\prime} \mathrm{Ar}=1 / 128$ & 140 & Suuberg et al. (2003) \\
\hline 17 & Sucrose & 760 & 0.1 & $\mathrm{O}_{2} / \mathrm{N}_{2}=0.267$ & 282 & Floess (1988) \\
\hline
\end{tabular}

A comparison of coal relative internal surface areas, depending on the react degree (Figure 5), shows that the model satisfactorily predicts internal specific surface area changes (and indirectly porosity changes) for coals and coal chars, while a poorer agreement is seen for active carbons and anthracites.

On the basis of Niwka coal experiments and literature data from Johnson (1975), Agrawal and Sears (1980), Floes et al. (1988), Suuberg et al. (2003) and Kulaots et al. (2004) a comparative analysis of matching the model to the assumed porosity change plots (for $n=0$ and $n=1$ ) was performed and presented in Figure 6. The analysis results show that a much better agreement is achieved for the value $\mathrm{n}=1$ which will be used in further analyses of changes in total active centres. 


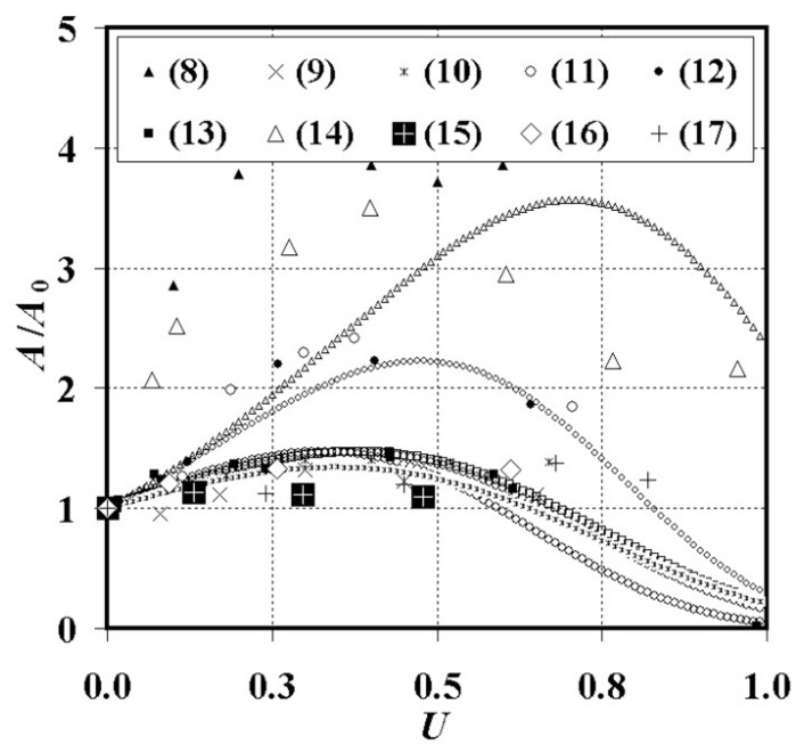

Fig. 5. Relationship between the internal surface area and the reaction degree
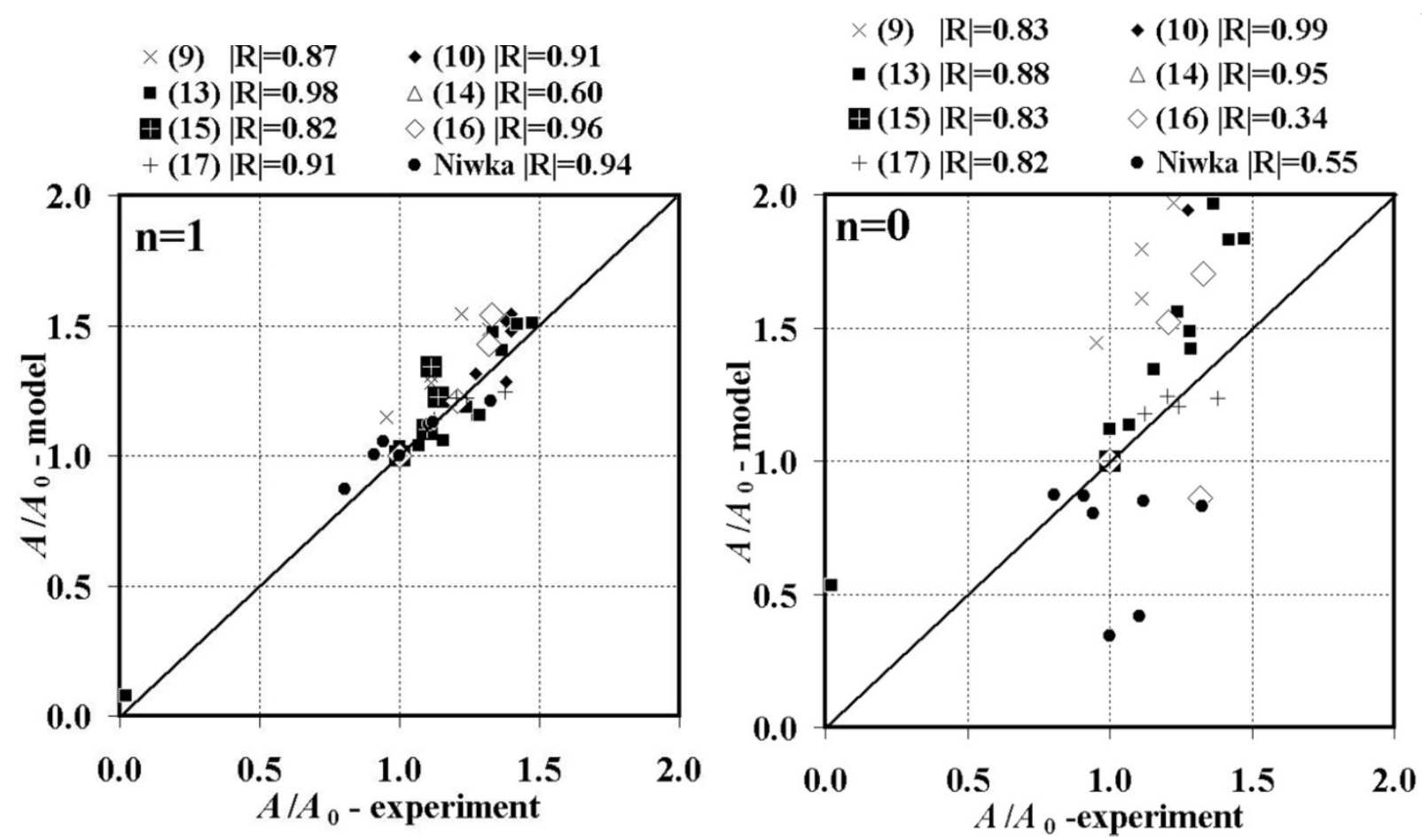

Fig. 6. Correlation of the models and the experimental series

\section{DETERMINATION OF CHANGES IN THE NUMBER OF ACTIVE CENTRES}

In coal and coal char (thermally processed fuel), an extremely important factor influencing surface stages of the combustion process is microstructure of the material being burned. Coal structure was assumed to contain many strongly defective and randomly distributed crystallites. The form of each of these crystallites can be recognised as a graphite allotrope with polytypes of hexagonal and rhombohedral lattices (Friese, 1962). In Figure 7, a typical configuration and the main lattice constants are presented. Such a structure contains active sites on margins and in the internal part which both react 
and mediate reactions. These sites are called active centres. Basing it on the analysis of coal, its composition and porosity as well as the internal surface area, it is possible to estimate the maximum number of active centres and numbers of compounds deriving from sulphur and nitrogen contained in coal. The determined numbers of active centres for a given type of coal give clear information on its reactivity, which enables more precise modelling of devolatilization, combustion and gasification processes under specific conditions in further analyses.

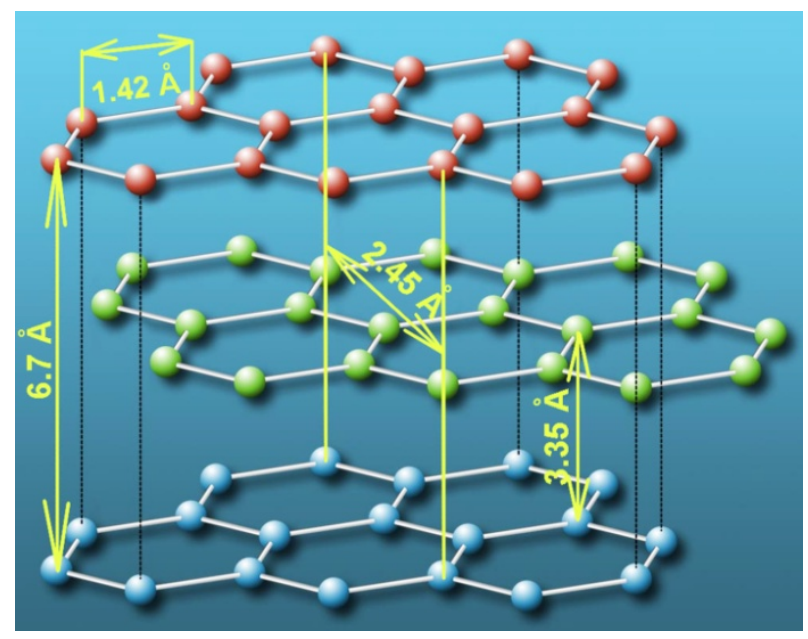

Fig. 7. Graphite monocrystal structure

Total active centres $S$ express a number of atoms on the reactant-accessible surface. For calculations of this value, statistical parameters are recommended. In theory, a monolayer evenly distributed on the whole surface of the reaction $A$ is assumed with a thickness equal to carbon atom diameter $\left(d_{C}=1.42 \cdot 10^{-10} \mathrm{~m}\right)$. Total active centres may also be defined as a volume of the reactive layer multiplied by the number of all carbon atoms inside a particle. For a unit of a substance amount, this value is determined by Avogadro's constant $N_{\mathrm{A}}$. In order to obtain an appropriate measurement unit, the volume fraction is calculated as the specific volume of the monolayer, $A d_{C}$, divided by the carbon molar volume $M_{C} / \rho_{C}$. The obtained value is the maximum number of reactive atoms, so the maximum total active centers $S_{\max }$, can be described as follows

$$
S_{\max }=N_{\mathrm{A}} \frac{A d_{\mathrm{C}} \rho_{\mathrm{p}}}{M_{\mathrm{C}}}, \text { particle } \cdot \mathrm{kg}^{-1} .
$$

In Equation (28), the apparent density is related to the true density through the porosity $\rho_{\mathrm{p}}=\rho_{\mathrm{r}}(1-\varepsilon)$. The so-called carbon matrix of a coal char particle was used in the model, where the global size of the particle (determined from the diameter) is constant, while its reaction degree changes and determines both the reactive surface and the porosity of the particle. As a consequence, these values change the number of active centres. An additional structural factor, included in the equation describing the total active centers, is the so-called degree of packing $k_{\mathrm{p}}=S / S_{\max }$. The degree of packing, $k_{\mathrm{p}}$, was also defined as a proportion of crystalline form density (for graphite, it is $\rho_{\mathrm{r}}=2100 \mathrm{~kg} / \mathrm{m}^{3}$ ) and the atom density $\rho_{C}$ (the carbon atom mass was assumed $m_{\mathrm{C}}=1.99 \cdot 10^{-26} \mathrm{~kg}$ ). The degree of packing of active centers is required to determine the subatomic volume. Such formulation of the degree of packing equal to $k_{\mathrm{p}}=0.158$ only relates to pure carbon substance (graphite) and highly devolatilized coal char. When a particle contains additions composed of $\mathrm{C}, \mathrm{H}, \mathrm{O}, \mathrm{N}, \mathrm{S}$, an additive measure of the mean volume $\rho_{\mathrm{r}}=\sum_{\mathrm{i}} g_{\mathrm{i}} \rho_{\mathrm{i}}$ is proposed, where $g_{\mathrm{i}}$ is a mass fraction and $\rho_{i}$ is a density of the component $i$. Considering the degree of packing, an equation describing the maximum true number of active centers is obtained: 


$$
S=k_{\mathrm{p}} N_{\mathrm{A}} \frac{A d_{\mathrm{C}} \rho_{\mathrm{r}}(1-\varepsilon)}{M_{\mathrm{C}}}, \text { particle } \cdot \mathrm{kg}^{-1} .
$$

When initial porosity values, $\varepsilon_{0}$, and internal surface area values, $A_{0}$, are introduced into Equation (29), the value of initial total active centers, $S_{0}$, is determined, while after introduction of Equations (20) and (26) into (29), an equation determining the total active center changes $S$ is obtained. The $S / S_{0}$ ratio is the basis for the final equation determining the total active centres as a function of the particle reaction degree which is:

$$
S=S_{0} \frac{\left[1-\varepsilon_{0} \exp \left(-U \ln \varepsilon_{0}\right)\right] \exp \left\{-2 U \ln \varepsilon_{0}+a_{1}\left[1-\exp \left(-U \ln \varepsilon_{0}\right)\right]\right\}}{1-\varepsilon_{0}}
$$

In Table 4 , selected parameters $\left(\varepsilon_{0}, A_{0}, \rho_{r}\right)$ for three Polish coal char types that enable to determine the number of active centers with Equation (30) are presented. Equations (28) - (30) and the data from Table 4 were used to determine the value of the initial number of active centers $S_{0}$.

Table 4. Selected parameters of Polish coal chars

\begin{tabular}{|l|c|c|c|c|}
\hline Coal char & $\begin{array}{c}A_{0} \cdot 10^{-3} \\
{\left[\mathrm{~m}^{2} / \mathrm{kg}\right]}\end{array}$ & $\varepsilon_{0}$ & $\begin{array}{c}\rho_{r} \\
{\left[\mathrm{~kg} / \mathrm{m}^{3}\right]}\end{array}$ & Reference \\
\hline Siersza & 27.1 & 0.400 & 1210 & Gil (2002) \\
\hline Janina & 16.7 & 0.593 & 1390 & Gil (2003) \\
\hline Piast & 12.5 & 0.457 & 1320 & Gil (2003) \\
\hline
\end{tabular}

Table 5 presents a comparison of the number of initial active centres obtained in the present paper and the values calculated using Equation (11) for the discussed coal chars. The values of the initial numbers of active centres determined using Equations (28) - (30) are approximately 10 times lower than those obtained when Equation (11) is applied. It results from the lack of the degree of packing $k_{\mathrm{p}}$ in the cited paper (Gil, 2002).

Table 5. Total active centres of the selected chars

\begin{tabular}{|l|c|c|c|c|}
\hline \multirow{2}{*}{ Coal char } & \multicolumn{2}{|c|}{ Total active centres (Gil, 2002) } & \multicolumn{2}{c|}{ Total active centres (Eq. 11) } \\
\cline { 2 - 5 } & $\begin{array}{c}S_{0} \cdot 10^{5} \\
{[\mathrm{kmole} / \mathrm{kg}]}\end{array}$ & $\begin{array}{c}S_{0} \cdot 10^{-22} \\
{[\mathrm{particle} / \mathrm{kg}]}\end{array}$ & $\begin{array}{c}S_{0} \cdot 10^{5} \\
{[\mathrm{kmole} / \mathrm{kg}]}\end{array}$ & $\begin{array}{c}S_{0} \cdot 10^{-22} \\
{[\mathrm{particle} / \mathrm{kg}]}\end{array}$ \\
\hline Siersza & 3.68 & 2.21 & 38.4 & 23.11 \\
\hline Janina & 1.76 & 1.06 & 16.1 & 9.66 \\
\hline Piast & 1.67 & 1.01 & 16.0 & 9.65 \\
\hline
\end{tabular}

Figure 8 shows an increase in the total active centres as a function of the particle reaction degree for coal char with the initial $d_{0}=0,9 \cdot 10^{-3} \mathrm{~m}$, for our calculations and calculations using the data from (Gil, 2002; Stanmore, 1991). In the model presented in these papers, individual coal characteristics are not taken into consideration, as a result of which one line represents all the three cases. For the particle reaction degree value of up to 0.4 , both models provide the same results, while above this value, in our model, increases in total active centres are higher, which results from a deeper analysis of porosity changes during coal conversion processes. 


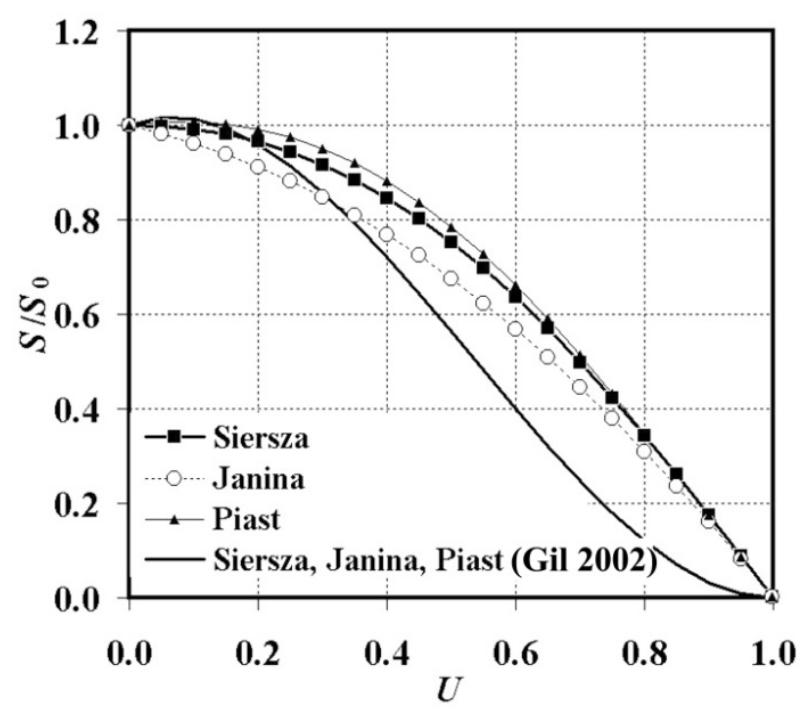

Fig. 8. Increase in the total active centres as a function of the reaction degree of the coal char particle with the initial size $d=0,9 \cdot 10^{-3} \mathrm{~m}$

Figure 9 shows the relationship between internal surface area changes and the increase in the number of active centres in a particle. For coal containing mineral substance, despite an entire loss of active centres, a skeleton of internal mineral substance remains, which we tried to show (Figure 9). On the basis of the available data (Table 4) and Equation (22) from Smith (1970), the increase in the mean pore radius as a function of the char coal reaction degree $r_{\mathrm{p}}$ was estimated (Figure 10).

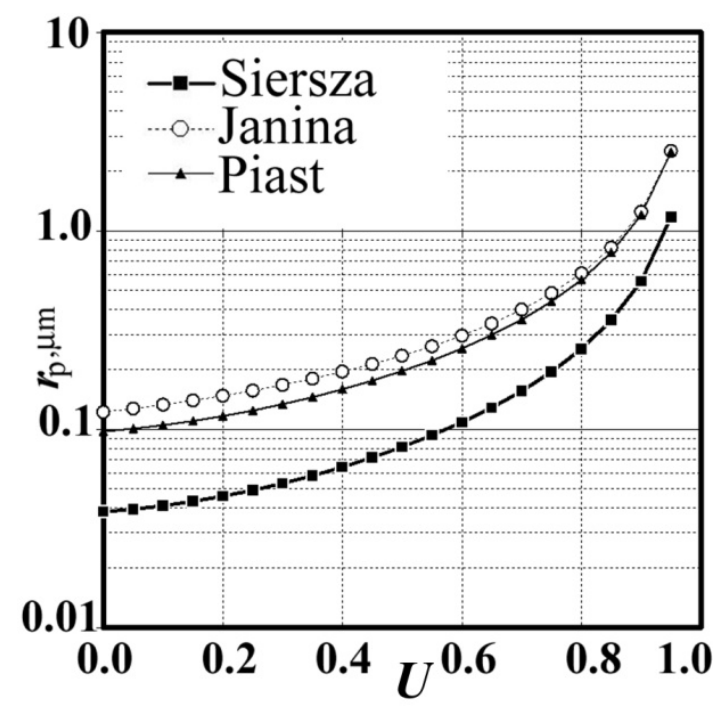

Fig. 9. Hysteresis loop for an increase in the total active centres as a function of coal char internal surface area development

\section{CONCLUSIONS}

- The equations obtained in the present paper enable modelling of the course of coal particle structural changes during its conversion in a wide range of its reaction degrees.

- The equations that enable determination of porosity changes were presented and their forms only depend on the initial particle porosities and their reaction degrees. 
- The analysis of consistency between the internal surface area modelling results and the study results for 10 coal types, reacting under different process conditions, shows that higher accuracy is achieved for the porosity described by Equation (20).

- Total active centres are related to the internal surface area and porosity of a particle. For a specific coal type, this value depends on the porosity, true density and size of the particle. Changes in total active centres, when these structural properties during thermal conversion of coal are considered, are described by Equation (30).

\section{SYMBOLS}

$\begin{array}{ll}A & \text { surface area, } \mathrm{m}^{2} / \mathrm{kg}, \mathrm{m}^{2} / \mathrm{kmol} \\ A & \text { ash content in coal } \\ a & \text { matching constant } \\ C & \text { carbon content in coal } \\ d & \text { particle diameter, } \mathrm{m} \\ E & \text { activation energy, } \mathrm{kJ} / \mathrm{mol} \\ g & \text { mass fraction } \\ H & \text { hydrogen content in coal } \\ K & \text { coefficient } \\ k_{1} & \text { kinetic coefficient, } 1 / \mathrm{s} \\ k_{2}, k_{3} & \text { coefficient } \\ k_{p} & \text { packing degree, }- \\ m & \text { mass, kg } \\ N & \text { nitrogen content in coal } \\ N_{A} & \text { Avogadro constant, } 1 / \mathrm{mol} \\ R & \text { gas constant, } \mathrm{kJ} /(\mathrm{molK}) \\ r & \text { radius, } \mathrm{m} \\ S & \text { sum of active sites, } \mathrm{kmol} / \mathrm{kg}, \text { particle } / \mathrm{kg} \\ S & \text { sulphur content in coal } \\ T & \text { temperature, } \mathrm{K} \\ \dot{T} & \text { heating rate, } \mathrm{K} / \mathrm{s} \\ t & \text { time, } \mathrm{s} \\ U & \text { react degree, }- \\ V & \text { volatile matter content in coal } \\ W & \text { water content in coal }\end{array}$

\section{Greek symbols}

$\varepsilon \quad$ solid particle porosity

$\vartheta \quad$ part of active sites

$\rho$ density, $\mathrm{kg} / \mathrm{m}^{3}$

\section{Superscripts}

a analytical state

waf water ash free state

wf water free state

$n \quad$ exponent

\section{Subscripts}

$\begin{array}{ll}0 & \text { initial value } \\ 1 & \text { final value }\end{array}$




$\begin{array}{ll}\infty & \text { denotes the value for time } \mathrm{t} \rightarrow \infty \\ i & \mathrm{i} \text {-th species } \\ j & \mathrm{j} \text {-th reaction } \\ \max & \text { maximum value } \\ \min & \text { minimum value } \\ p & \text { particle, devolatilization conditions } \\ r & \text { crystalline form }\end{array}$

\section{REFERENCES}

Agrawal A.K., Sears J.T., 1980. The coal char reactions with $\mathrm{CO}_{2}-\mathrm{CO}$ gas mixtures. Ind. Eng. Chem. Process Des. Dev., 19, 364-371. DOI: 10.1021/i260075a006.

Anthony D.B., Howard J.B., 1976. Coal devolatilization and hydrogasification. AIChE J., 22, 625-656. DOI: 10.1016/0016-2361(76)90008-9.

Blackwood J.D., McCarthy D.J., 1966. The mechanism of hydrogenation of coal to methane. Aust. J. Chem., 19, 797-813. DOI:10.1071/CH9660797.

Croiset E., Heurtaebise C., Rouan J.P., Richarad J.R., 1998. Influence of pressure on the heterogeneous formation and destruction of nitrogen oxides during char combustion. Combust. Flame, 112, 33-44. DOI:10.1016/S00102180(97)81755-5.

Croiset E., Mallet Ch., Rouan J.P., Richard J.R., 1996. The influence of pressure on char combustion kinetics. 26th International Symposium on Combustion. The Combustion Institute, Pittsburgh, 3096-3102. DOI: 10.1016/S0082-0784(96)80153-6.

Feng B., Bhatia S. K., 2003. Variation of the pore structure of coal chars during gasification. Carbon, 41, 507523. DOI:10.1016/S0008-6223(02)00357-3.

Floess J.K., Longwell J.P., Sarofim A.F., 1988. Intrinsic reaction kinetics of microporous carbons. 1. Noncatalyzed chars. Energy Fuels, 2, 18-26. DOI: 10.1021/ef00007a004.

Freise E. J., 1962. Structure of graphite. Nature, 193, 671-672. DOI: 10.1038/193671a0.

Gil S., 2000. Research on the influence of pressure on kinetics of coal nitrogen conversion during pyrolysis and combustion. $\mathrm{PhD}$ Thesis. Silesian University of Technology, Katowice.

Gil S., 2002. Influence of combustion pressure on fuel-N conversion to $\mathrm{NO}, \mathrm{N}_{2} \mathrm{O}$ and $\mathrm{N}_{2}$. Karbo, 9, $272-275$.

Gil S., 2003. Kinetics of heterogeneous nitrogen oxides formation during pressurized char combustion. Grant KBN PAN No. 4 T10B 029 22, 1075/T10/2002/22.

Hurt R.H., Sarofim A.F., Longwell J.P., 1991. Effect of nonuniform surface reactivity on the evolution of pore structure and surface area during carbon gasification. Energy Fuels, 5, 463-468. DOI: 10.1021/ef00027a018.

Johnson J.L., 1987. Kinetics of coal gasification. John Wiley \& Sons, New York.

Johnson J.L., 1975. Relationship between the gasification reactivities of coal char and the physical and chemical properties of coal and coal char. American Chemical Society, Division of Fuel Chemistry, 20, 85-102.

Kothandaraman G., Simons G.A., 1984. Evolution of the pore structure in PSOC140 liquite during pyrolysis. 20th International Symposium on Combustion. The Combustion Institute, Pittsburgh, 1523-1529. DOI: 10.1016/S0082-0784(85)80646-9.

Kowol J., Tomeczek J., 1988. Kinetics of main products formation during coal devolatilization. Erdöl und Kohle, 41, 161-165.

Krammer G.F., Sarofim A.F., 1994. Reaction of char nitrogen during fluidized bed coal combustion - influence of nitric oxide and oxygen on nitrous oxide. Combust. Flame, 97, 118-124. DOI: 10.1016/0010-2180(94)90120-1.

Külaots I., Aarna I., Calleyo M., Hurt R.H., Suuberg E.M., 2002. Development of porosity during coal char combustion. Proc. Combust. Inst., 23, 495-501. DOI:10.1016/S1540-7489(02)80064-5.

Laine N.R., Vastola F.J., Walker P.L., 1963. The importance of active surface area in the carbon-oxygen reaction. J. Phys. Chem., 67, 2030-2034.

Mlonka J., 1992. Research over the kinetics of structural changes and theirs influence on coal pyrolysis process. $\mathrm{PhD}$ Dissertation. Silesian University of Technology, Katowice. 
Simons G.A., 1984. Coal pyrolysis. II. Species transport theory. Combust. Flame, 55, $181-194$. DOI:10.1016/0010-2180(84)90026-9.

Smith J.M., 1970. Chemical engineering kinetics. McGraw Hill, New York.

De Soete G.G., 1990. Heterogeneous $\mathrm{N}_{2} \mathrm{O}$ and $\mathrm{NO}$ formation from bound nitrogen atoms during coal char combustion. 23rd International Symposium on Combustion. The Combustion Institute, Pittsburgh, 1257-1264. DOI:10.1016/S0082-0784(06)80388-7.

Solomon P.R., Colket M.B., 1978. Evolution of fuel nitrogen in coal devolatilization. Fuel, 57, 749-755. DOI:10.1016/0016-2361(78)90133-3.

Sotirchos S.V., 1987. On a class of random pore and particle models for gas-solid reactions. Chem. Eng. Sci., 42, 1262-1265. DOI: 10.1016/0009-2509(87)80084-2

Stanmore B.R., 1991. Modeling of combustion behavior of petroleum coke. Combust. Flame, 83, $221-227$. DOI:10.1016/0010-2180(91)90070-R.

Suuberg E.M., Peters W.A.,Howard J.B., 1979. Product compositions and formation kinetics in rapid pyrolysis of pulverized coal - implications for combustion. 17th International Symposium on Combustion. The Combustion Institute, Pittsburgh, 117-130. DOI:10.1016/S0082-0784(79)80015-6.

Suuberg E.M., Külaots I., Aarna I., Calleyo M., Vrager A., Deutsch D., 2003. Study of activation of coal char. Proceedings of the DOE Grants DE-FG 26 99FT-40582.

Tomeczek J., Gil S., 1995. Kinetics of porosity evolution during fast heating of coal. 8th International Conference on Coal Science, Oviedo, 925-928.

Tomeczek J., Gil S., 2003. Volatiles release and porosity evolution during high pressure coal pyrolysis. Fuel, 82, 285-292. DOI:10.1016/S0016-2361(02)00256-9.

Visona S.P., Stanmore B.R., 1996. Modeling $\mathrm{NO}_{\mathrm{x}}$ release from a single coal particle. II. Formation of NO from char-nitrogen. Combust. Flame, 106, 207-218. DOI: 10.1016/0010-2180(95)00257-X. 